\title{
Recurrent Bilateral Focal Myositis
}

\author{
Hiroko Nagafuchi ${ }^{1}$, Hiromasa Nakano ${ }^{1}$, Seido Ooka ${ }^{1}$, Yukiko Takakuwa ${ }^{1}$, Hidehiro Yamada ${ }^{1}$, \\ Mamoru Tadokoro ${ }^{2}$, Sadatomo Shimojo ${ }^{1}$ and Shoichi Ozaki ${ }^{1}$
}

\begin{abstract}
This report describes a rare case of recurrent bilateral focal myositis and its successful treatment via methotrexate. A 38-year-old man presented myalgia of the right gastrocnemius in May 2005. Magnetic resonance imaging showed very high signal intensity in the right gastrocnemius on short-tau inversion recovery images. A muscle biopsy revealed inflammatory CD4+ cell-dominant myogenic change. Focal myositis was diagnosed. The first steroid treatment was effective. Tapering of prednisolone, however, repeatedly induced myositis relapse, which progressed to multiple muscle lesions of both lower limbs. Initiation of methotrexate finally allowed successful tapering of prednisolone, with no relapse in the past 4 years.
\end{abstract}

Key words: focal myositis, recurrence, bilateral, nemaline, methotrexate

(Intern Med 55: 3369-3374, 2016)

(DOI: 10.2169/internalmedicine.55.7172)

\section{Introduction}

Focal myositis is an idiopathic inflammatory myopathy and a rare inflammatory pseudotumor of the skeletal muscle with unknown etiology (1). The disease typically disappears spontaneously, does not last more than 4 years, and has no recurrence $(1,2)$. This myositis can be treated successfully with steroids or nonsteroidal anti-inflammatory drugs (NSAIDs) $(1,2)$. We herein describe the case of a man with recurrent episodes of bilateral focal myositis.

\section{Case Report}

A 38-year-old man presented with myalgia of the right gastrocnemius muscle in May 2005. A needle biopsy of the muscle was performed in another hospital and indicated no malignancy. The patient did not receive any treatment at this time. As his symptom did not improve, he visited our hospital in August 2005 with tenderness of the right gastrocnemius muscle. On physical examination, the vital signs were normal. No significant signs were detected on the skin, cardiovascular, respiratory, or abdominal examinations. Manual muscle testing indicated full scores except in the right gastrocnemius, which demonstrated grade 4 (of 5) because of myalgia. Evaluations of his mental status, sensory, and cerebellar systems were normal. Tendon reflexes and sensitivity of the upper and lower limbs were also normal. Laboratory data indicated that the patient's serum creatine kinase (CK), aldolase, myoglobin, erythrocyte sedimentation rate (ESR), and C-reactive protein (CRP) were within normal limits, and anti-Jo-1 autoantibody, anti-ARS autoantibody, and antinuclear antibody were negative (Table). Monoclonal gammopathy was not detected. Hepatitis B surface antigen (HBs Ag) was positive (cut-off $>2,000$ ), and HB virus DNA was negative (<3.7 LEG/mL). Human immunodeficiency virus (HIV) and hepatitis $\mathrm{C}$ virus antibody tests were negative (Table). Deep vein thrombosis was ruled out by echo of the limbs.

Electromyography was not performed because the patient was unable to cooperate due to myalgia. Magnetic resonance imaging (MRI) revealed very high signal intensity in the right gastrocnemius medial head muscle on a short-tau inversion recovery (STIR) image. Atrophic change of the muscle was also noted (Fig. 1a and b). A muscle biopsy of the right gastrocnemius revealed interstitial muscle infiltration by mononuclear inflammatory cells without findings of vasculitis, along with muscle fiber necrosis and regeneration (Fig. 2a and b).

Immunohistochemical staining of the muscle biopsy showed that the infiltrating cells predominantly consisted of

${ }^{1}$ Division of Rheumatology, Department of Internal Medicine, St. Marianna University School of Medicine, Japan and ${ }^{2}$ Department of Pathology, St. Marianna University School of Medicine, Japan

Received for publication January 22, 2016; Accepted for publication March 9, 2016

Correspondence to Dr. Hiroko Nagafuchi, h3naga@marianna-u.ac.jp 
Table. Laboratory Findings in August 2005.

\begin{tabular}{lrlrlr}
\hline WBC & $6,900 / \mu \mathrm{L}$ & TP & $7.9 \mathrm{~g} / \mathrm{dL}$ & IgG & $1,406 \mathrm{mg} / \mathrm{dL}$ \\
Neut & $65.1 \%$ & Alb & $4.8 \mathrm{~g} / \mathrm{dL}$ & IgA & $261 \mathrm{mg} / \mathrm{dL}$ \\
Ly & $23.3 \%$ & T-Bil & $0.7 \mathrm{mg} / \mathrm{dL}$ & IgM & $130 \mathrm{mg} / \mathrm{dL}$ \\
Mono & $5.1 \%$ & AST & $14 \mathrm{IU} / \mathrm{L}$ & C3 & $131 \mathrm{mg} / \mathrm{dL}$ \\
Eosino & $6.2 \%$ & ALT & $16 \mathrm{IU} / \mathrm{L}$ & C4 & $24 \mathrm{mg} / \mathrm{dL}$ \\
Baso & $0.3 \%$ & LDH & $134 \mathrm{IU} / \mathrm{L}$ & CH50 & $44.4 \mathrm{U} / \mathrm{mL}$ \\
RBC & $4.82 \times 10^{6} / \mu \mathrm{L}$ & CK & $74 \mathrm{IU} / \mathrm{L}$ & antinuclear antibody & $<40$ \\
Hb & $14.7 \mathrm{~g} / \mathrm{dL}$ & ALP & $223 \mathrm{IU} / \mathrm{L}$ & anti-Jo-1 autoantibody & negative \\
Hct & $41.9 \%$ & BUN & $11.4 \mathrm{mg} / \mathrm{dL}$ & anti-ARS autoantibody & negative \\
Plt & $31.5 \times 10^{4} / \mu \mathrm{L}$ & Cre & $0.78 \mathrm{mg} / \mathrm{dL}$ & Hepatitis B surface antigen & positive \\
ESR & $6 \mathrm{~mm} / \mathrm{h}$ & CRP & $0.11 \mathrm{mg} / \mathrm{dL}$ & anti-HCV antibody & negative \\
& & & & HBV-DNA* & $<3.7 \mathrm{LEG} / \mathrm{mL}$ \\
\hline
\end{tabular}

*transcription-mediated amplification assay.
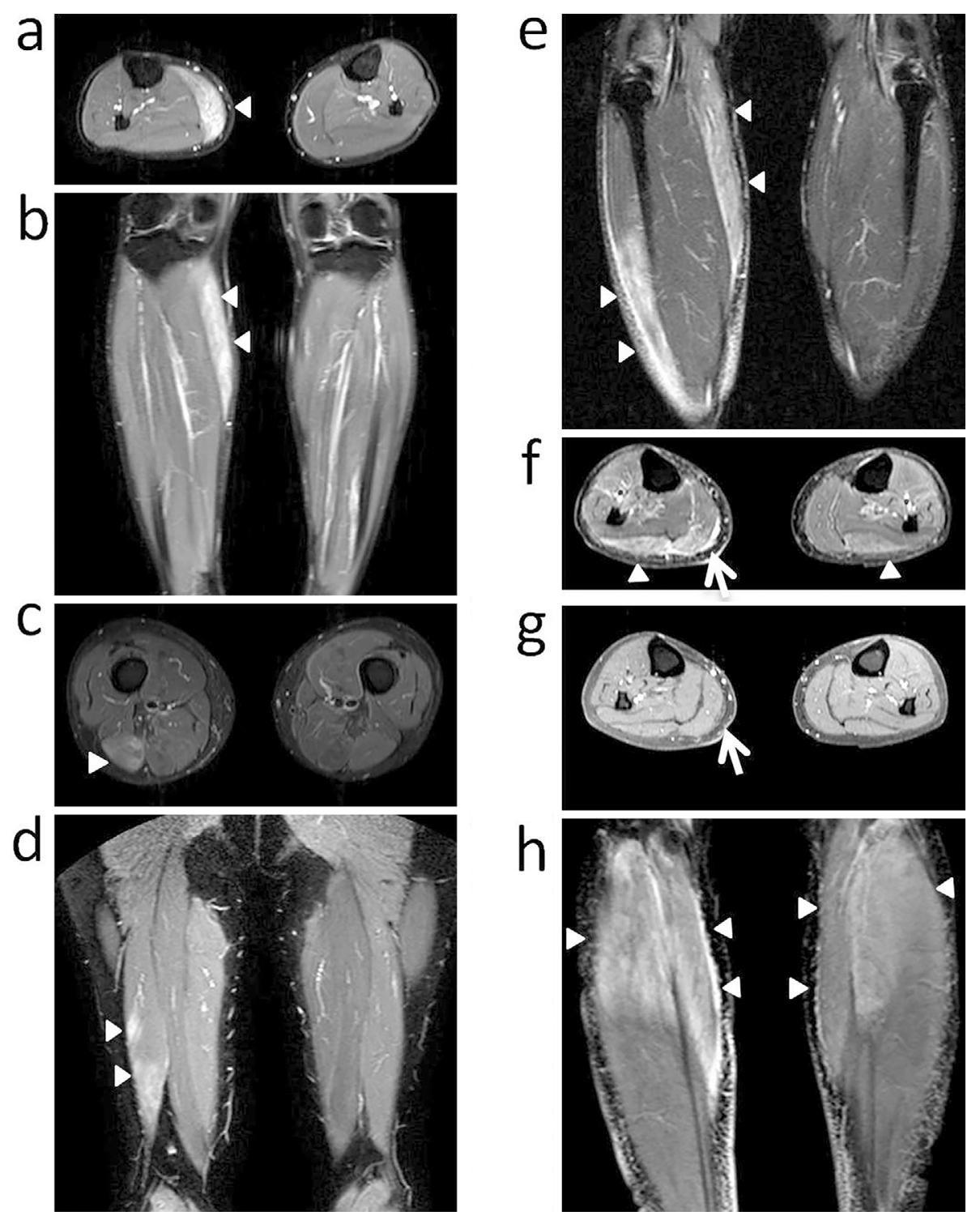

Figure 1. Magnetic resonance imaging (MRI) of the lower limbs. a, b: August 2005; c, d, e: June 2006; f, g, h: January 2008. a, b, e, f, h: Axial (a, f) and coronal (b, e, h). a-f: Unenhanced MRI image and g: gadolinium-enhanced MRI image. STIR images show high signal intensity in the affected muscles of the lower legs (white arrowhead). c, d: Axial and coronal STIR images show high signal intensity in the affected femoral muscles (white arrowhead). f, g: Axial gadolinium-enhanced MRI (g) shows no enhanced area in the thickened fascia of the right gastrocnemius, which showed high signal intensity on the unenhanced MRI image (f) (white arrow). 
a

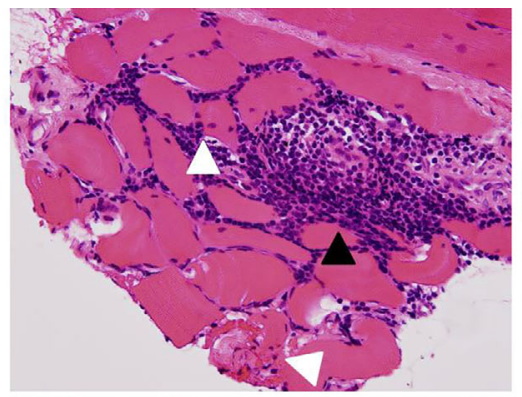

b

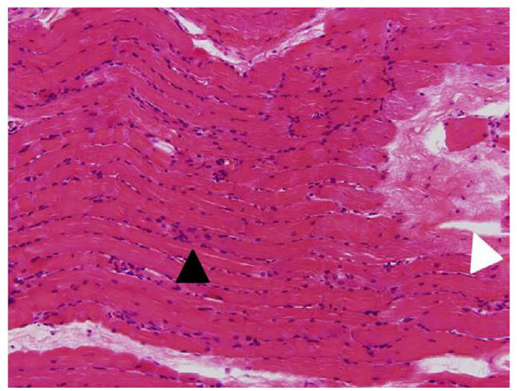

C

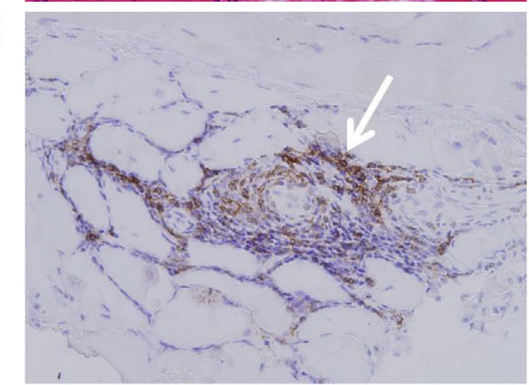

d

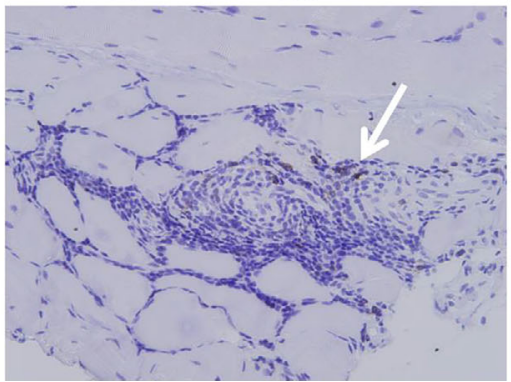

e

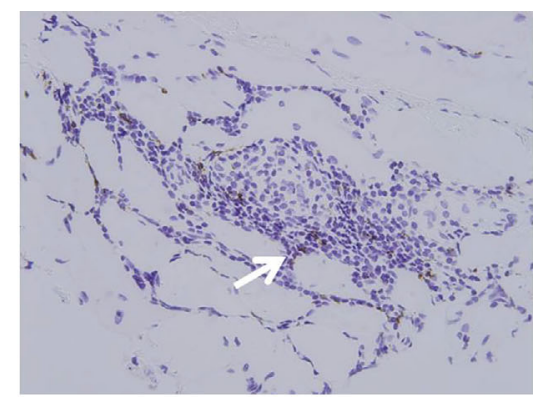

$\mathrm{f}$

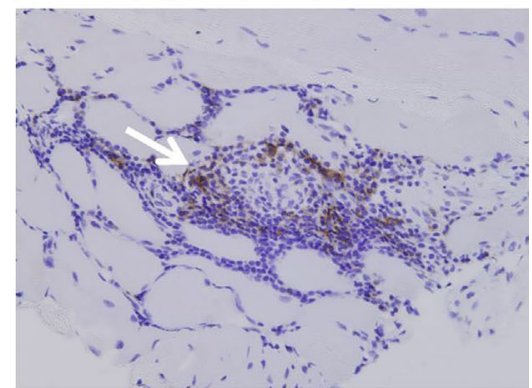

g

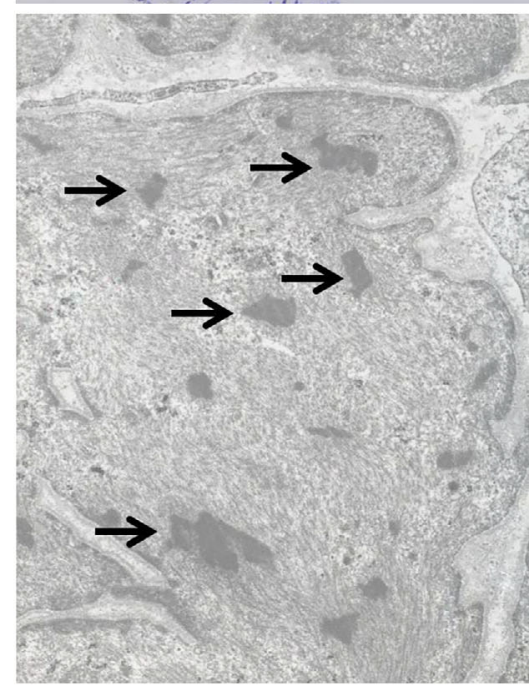

Figure 2. Muscle biopsy. a, b: Hematoxylin and Eosin staining, 400x; c-f: immunohistochemical staining, 400×; c: CD4; d: CD8; e: CD68; f: CD20; g: electron microscopy. A muscle biopsy of the right gastrocnemius reveals mononuclear inflammatory cells (a, b: black arrowhead) that infiltrated the interstitial spaces of the muscle without vasculitis findings, along with muscle fiber necrosis and regeneration ( $a$, b: white arrowhead). Infiltrating cells predominantly consisted of $\mathrm{CD4}+\mathrm{T}$ cells, CD68+macrophages, and CD20+B cells accompanied by a few CD8+T cells (c-f: white arrow). Electron microscopy of the muscle biopsy specimens reveals nemaline rods (g: black arrows).

CD4+ T cells, CD68+ macrophages, and CD20+ B cells accompanied by a few CD8+ T cells (Fig. 2b-f). Focal myositis was diagnosed.

As the patient was $\mathrm{HBs} \mathrm{Ag}$-positive, lamivudine treatment was initiated for the prevention of de novo hepatitis under immunosuppressive conditions. Prednisolone (PSL) $(30 \mathrm{mg} /$ day) was administered to treat the focal myositis in September 2005, and his symptoms and MRI findings were immediately improved. The clinical course is shown in Fig. 3. The PSL dosage was tapered to $15 \mathrm{mg}$ daily in April 2006. The patient's muscle pain worsened gradually at around this time, and walking became difficult without a cane in June
2006. Although his CRP level was $0.4 \mathrm{mg} / \mathrm{dL}$, the serum myogenic enzyme level was not re-elevated. MRI revealed multiple high-intensity areas in the lower limbs that included the femoral muscle (both sides of the vastus lateralis, the left vastus intermedius, the right biceps femoris, and the left gracilis) (Fig. 1c and d) and the right gastrocnemius (Fig. 1e) on STIR images. The myositis had expanded to both lower limbs and worsened. The PSL dosage was increased to $60 \mathrm{mg} / \mathrm{day}$ for relapse of myositis, and the patient's symptoms immediately improved.

After tapering the PSL dosage to $17.5 \mathrm{mg} /$ day, a second myositis relapse occurred in October 2007. The myositis 


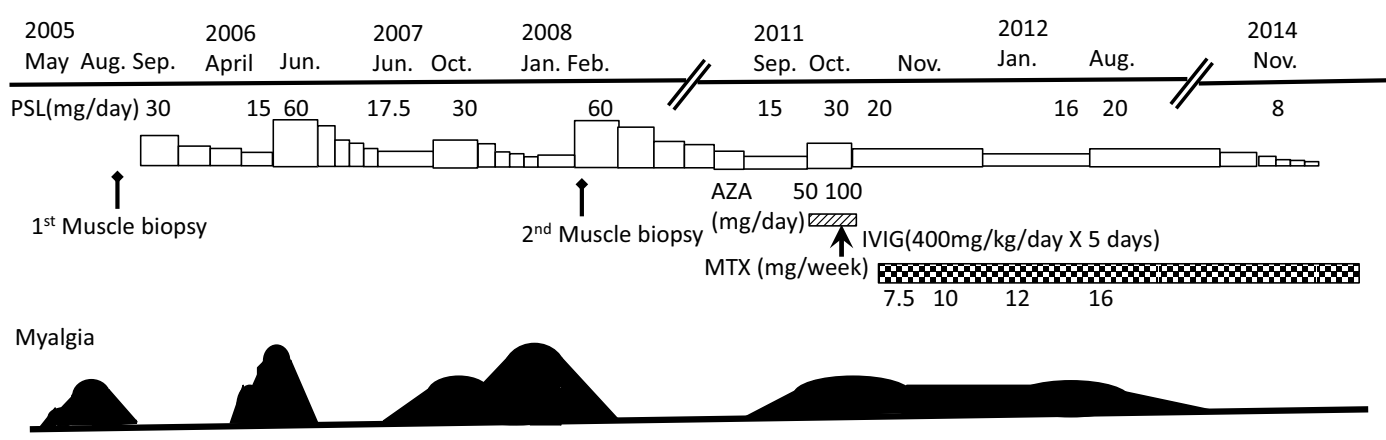

Figure 3. Clinical course of the patient. PSL: prednisolone, MTX: methotrexate, AZA: azathioprine, IVIG: high-dose intravenous immunoglobulin

again worsened. MRI findings revealed high signal intensity of the bilateral gastrocnemius (Fig. 1f and h), left popliteus muscle, and right semimembranosus on STIR images (data not shown), and mild edema was evident in the subcutaneous tissue in both lower limbs in January 2008. As thickening of the fascia of the right gastrocnemius on the STIR image (Fig. 1f, white arrow) demonstrated no gadolinium contrast enhancement (Fig. 1g, white arrow), it was considered to result from edema. Because the patient was unusually resistant to the treatment for focal myositis, we performed a muscle biopsy of the left gastrocnemius to re-confirm the diagnosis, which showed a similar result to the first biopsy (data not shown). Electron microscopy of the muscle biopsy specimens in February 2008 revealed nemaline rods (Fig. $2 \mathrm{~g}$, black arrows). The dosage of PSL was again increased to $60 \mathrm{mg} /$ day for the third relapse of myositis.

Thereafter, we administered azathioprine (max $100 \mathrm{mg}$ / day) for a steroid-sparing effect, but it failed to bring the patient persistent relief from his myalgia and gait disturbance. Therefore, we were forced to continue to administer $15 \mathrm{mg}$ / day or more of the steroid in order to maintain remission. In September 2011, the relapse of myositis involved myalgia of both lower limbs and arthralgia of both foot joints. The patient's PSL dosage was increased from $15 \mathrm{mg} /$ day to $30 \mathrm{mg}$ / day, however, the effect was incomplete. As he had a compression fracture of the vertebrae due to steroid-induced osteoporosis, high-dosage PSL treatment was avoided. Intravenous immunoglobulin (IVIG) failed to induce remission. Methotrexate (MTX) (7.5 mg/week) was initiated with PSL $20 \mathrm{mg} /$ day in October 2011, as hepatitis B virus (HBV) infection had been controlled by lamivudine. The dosage of MTX was gradually increased to $16 \mathrm{mg} /$ week by August 2012. We decreased the PSL dosage to $8 \mathrm{mg} /$ day in November 2014. The patient has had no myositis relapse since 2011. MRI findings in December 2014 revealed no inflammatory change (Fig. 1f). The patient can maintain standing on his heels, but not on his tiptoes. We consider this issue to indicate muscle weakness as a sequela of myositis.

\section{Discussion}

This patient had myositis that developed in the right gas- trocnemius muscle. The differential diagnoses of inflammatory myopathy were postulated to be polymyositis, dermatomyositis, inclusion body myositis, eosinophilic myositis, and sarcoidosis. He had no past medical history and no other organ disorders including those affecting the skin and lung. The lesion originated from the distal muscle, with no eosinophilia or increase of CK or CRP in the peripheral blood. The pathology of the muscle biopsy revealed myositis and did not indicate granulomas, eosinophilic infiltration, or vacuoles. Therefore, focal myositis was diagnosed.

Focal myositis is a type $\mathrm{V}$ idiopathic inflammatory myopathy, classified by Bohan and Peter as miscellaneous myopathies (3). Focal myositis is a rare, broad spectrum disease (1, 2, 4-10). The levels of acute phase reactants and myogenic enzymes, such as CK, and the site of the involved muscle also vary in myositis $(1,2,4-10)$. In this case, the patient's myalgia began in the right gastrocnemius and spread to both lower limbs. He had almost no elevation of serum CRP or CK.

The CRP and CK levels vary in focal myositis. Smith et al. reported that serum $\mathrm{CK}$ was normal in five of eight patients (2). Morevoer, Sekiguchi et al. reported that normal serum CRP and CK levels might be associated with mild muscle inflammation in patients with focal myositis (11). Although the mechanism of muscle pain is not fully understood, inflammatory muscle pain was related to molecules including interleukin (IL)-6, tumor necrosis factor-alpha, IL1beta, and kinin in experiments using animal models $(12,13)$. Dina et al. reported a novel experimental model of chronic muscle pain induced by mild acute muscle inflammation (14). In fact, the histopathological findings indicated muscle inflammation in the present patient. PSL is presumed to have led to the alleviation of symptoms by suppressing muscle inflammation.

The etiology of myositis is unknown. Some reports have reported an association between chronic HBV infection and myositis (15-17). Lamivudine or entecavir, antiviral therapies for HBV infection, improved symptoms in patients with myositis $(18,19)$. Toti et al. reported that the investigation of possible viral etiology via polymerase chain reaction was negative in focal myositis (20). BCG vaccine was also reported to trigger the onset of myositis (21). The present pa- 
tient was an HBV carrier, however, antiviral therapy did not affect his myositis. The relationship between $\mathrm{HBV}$ and myositis is unknown. Although electron microscopy of specimens from the second muscle biopsy revealed nemaline rods, we judged the finding to be a non-specific change because his clinical syndrome was not characteristic of nemaline myopathy (24), and there have been several reports concerning the non-specific finding of nemaline rods in inflammatory myopathies (polymyositis and dermatomyositis) (22-25).

The majority of focal myositis cases involve a limited lesion, and bilateral lesions are rare. In our case, the patient demonstrated myositis progression from the right gastrocnemius to both sides approximately 1 year after onset and recurrent myalgia, and the myositis had temporary femoral muscle involvement. Heffner $\mathrm{Jr}$ et al. reported six patients with polymyositis beginning as a focal process that rapidly progressed 3-6 months from the onset, and some cases of bilateral focal myositis have been reported (26). Additionally, some reports have discussed the difference between focal myositis and polymyositis $(27,28)$. Conversely, there are also some reports of polymyositis cases with distal muscle involvement or without elevation of serum CK (29-34). The muscle biopsy in our case showed mononuclear inflammatory infiltrates that predominantly consisted of CD4+ T cells. This finding is similar to that of dermatomyositis $(35,36)$. Previous studies also reported CD4+-dominant cell infiltration in the muscle in focal myositis $(37,38)$ and dermatomyositis $(35,36)$, but not in polymyositis (39). In our patient, muscle weakness derived from myalgia was present but not progressive, and his immunohistochemical findings indicated focal myositis rather than polymyositis. It appears that focal myositis and polymyositis have different pathophysiological mechanisms; however, whether focal myositis is a subtype of polymyositis remains to be determined.

Focal myositis usually shows a good response to treatment with PSL and NSAIDs (2). It has a good prognosis and might be a self-limiting disease (1-3). Recurrent cases are rare $(6,40-50)$. Furthermore, the response to NSAIDs is often good even in cases of repeated relapse (41-43), and some cases of spontaneous remission have occurred $(8,49)$. Steroid-resistant cases are also rare $(47,51)$. Although the present patient demonstrated a good response to steroid treatment, PSL dose reduction induced the recurrence of myalgia. Because he experienced repeated myositis relapses when the PSL dose was reduced to $15-17.5 \mathrm{mg}$, it became necessary to use immunosuppressive agents for a steroidsparing effect. Azathioprine and IVIG did not affect the patient's myositis. Because his HBV infection was successfully controlled with lamivudine, we used MTX and were able to reduce the PSL dose. Reports of immunosuppressive therapy for focal myositis are limited $(6,47,51,52)$, and only one previous case report, in a child, described MTX treatment for this condition (47). Further studies are needed in order to clarify the sparing effect of treatment via MTX in steroid- resistant cases of focal myositis.

The authors state that they have no Conflict of Interest (COI).

\section{Acknowledgement}

We would like to thank Dr. A. Yamakawa at St. Marianna University School of Medicine for data collection. We are grateful to Dr. I. Nishino at the National Center of Neurology and Psychiatry for helpful discussions.

\section{References}

1. Heffner RR Jr, Armbrustmacher VW, Earle KM. Focal myositis. Cancer 40: 301-306, 1977.

2. Smith AG, Urbanits S, Blaivas M, Grisold W, Russel JW. Clinical and pathologic features of focal myositis. Muscle Nerve 23: 1569$1575,2000$.

3. Bohan A. History and classification of polymyositis and dermatomyositis. Clin Dermatol 6: 3-8, 1988.

4. Yanmaz Alnigenis MN, Kolasinski SL, Kalovidouris AE. Focal myositis: a review of 100 previously published cases and a report of 2 new cases. Clin Exp Rheumatol 17: 631, 1999.

5. McCluggage WG, Mirakhur M. Focal myositis of the floor of mouth: report of two cases and review of the literature. Oral Surg Oral Med 81: 573-575, 1996.

6. Naggar EA, Kanda F, Okuda S, et al. Focal myositis in monozygotic twins. Intern Med 43: 599-601, 2004.

7. Isaacson G, Chan KH, Heffner RR Jr. Focal myositis. A new cause for the pediatric neck mass. Arch Otolaryngol Head Neck Surg 17: 103-105, 1991.

8. Finger R, Dennis G. Focal myositis. J Rheumatol 22: 188-189, 1995.

9. Naumann M, Toyka KV, Goebel HH, Hofmann E, Reichmann H. Focal myositis of the temporal muscle. Muscle Nerve 16: 13741376, 1993.

10. Gomez Rodriguez N, Formio Rodriguez E, Ibanez Ruan J, Irisarri Castro C, Ferreiro Seoane JL. Pseudotumor in the forearm caused by focal myositis. A rare form of idiopathic inflammatory myopathy. Ann Med Intern 13: 398-400, 1996.

11. Sekiguchi K, Kanda F, Oishi K, et al. HLA typing in focal myositis. J Neurol Sci 227: 21-25, 2004.

12. Dina OA, Green PG, Levine JD. Role of interleukin-6 in chronic muscle hyperalgesic priming. Neuroscience 52: 521-525, 2008.

13. Meotti FC, Campos R, da Silva K, et al. Inflammatory muscle pain is dependent on the activation of kinin $\mathrm{B} 1$ and $\mathrm{B} 2$ receptors and intracellular kinase pathways. $\mathrm{Br} \mathrm{J}$ Pharmacol 166: 1127$1139,2012$.

14. Dina OA, Levine JD, Green PG. Muscle inflammation induces a protein kinase Cepsilon-dependent chronic-latent muscle pain. J Pain 9: 457-462, 2008.

15. Mihas AA, Kirby JD, Kent SP. Hepatitis B antigen and polymyositis. JAMA 239: 221-222, 1978.

16. Pittsley RA, Shearn MA, Kaufman L. Acute hepatitis B simulating dermatomyositis. JAMA 239: 959, 1978.

17. Nojima T, Hirakata M, Sato S, et al. A case of polymyositis associated with hepatitis B infection. Clin Exp Rheumatol 18: 86-81, 2000.

18. Gruber-Wackernagel A, Scarpatetti M, Gruber MJ, Hermann J, Aberer E. Subacute cutaneous lupus erythematosus and interstitial myositis occurring with hepatitis B infection: response to antiviral therapy with lamivudine. J Clin Rheumatol 14: 346-349, 2008.

19. Wong MH, Sockalingam S, Zain A. Polymyositis associated with hepatitis B: management with entacavir and prednisolone. Int $\mathrm{J}$ Rheum Dis 14: e38-e41, 2011.

20. Toti P, Romano L, Villanova M, Zazzi M, Luzi P. Focal myositis: 
a polymerase chain reaction analysis for a viral etiology. Hum Pathol 28: 111-113, 1997.

21. Manganelli S, De Stefano R, Malandrini A, et al. Bilateral recurrent focal myositis of gastrocnemius muscles after BCG vaccination. Rheumatology 41: 1074-1076, 2002.

22. Letournel F, Le Clec'h C, Croué A, Marcorelles P, Lavigne C, Pénisson-Besnier I. Nemaline bodies as unique pathological feature in the course of treated dermatomyositis. Clin Neuropathol 29: $357-360,2010$

23. Danon MJ, Giometti CS, Manaligod JR, Perurena OH, Skosey JL. Adult-onset nemaline rods in a patient treated for suspected dermatomyositis. Study with two-dimensional electrophoresis. Arch Neurol 38: 761-766, 1981.

24. Sun AP, Ohtsuki Y, Yano T, et al. Typical nemaline bodies presenting in a patient with polymyositis. Med Electron Microsc 35: 167172, 2002.

25. Cape CA, Johnson WW, Pitner SE. Nemaline structures in polymyositis. A nonspecific pathological reaction of skeletal muscles. Neurology 20: 494-502, 1970.

26. Heffner RR Jr, Barron SA. Polymyositis beginning as a focal process. Arch Neurol 38: 439-442, 1981.

27. Melzer N, Wessig C, Ulzheimer J, et al. Distal-symmetric focal inflammatory myopathy distinct from focal myositis and polymyositis. Muscle Nerve 40: 309-312, 2009.

28. Flaisler F, Blin D, Asencio G, Lopez FM, Combe B. Focal myositis: a localized form of polymyositis? J Rheumatol 20: 1414-1416, 1993.

29. Dimitri D, Dubourg O, Maisonobe T, et al. Distal inflammatory myopathy: unusual presentation of polymyositis or new entity? Neuromuscul Disord 18: 493-500, 2008.

30. Marconi G, Ronchi O, Taiuti R. Polymyositis with severe distal muscular involvement. Acta Neurol 4: 340-346, 1982.

31. Sundaram MB, Ashenhurst EM. Polymyositis presenting with distal and asymmetrical weakness. Can J Neurol Sci 8: 147-149, 1981.

32. Altindag O. A patient with polymyositis and normal serum creatine kinase level. J Clin Rheumatol 13: 50-51, 2007.

33. Gran JT, Myklebust G, Johansen S. Adult idiopathic polymyositis without elevation of creatine kinase. Case report and review of the literature. Scand J Rheumatol 22: 94-96, 1993.

34. Tütüncüoğlu S, Tekgül H, Demirtaş E, Uysal S. Infantile polymyositis with normal serum creatine kinase level. Brain Dev 19: 63-65, 1997.

35. Arahata K, Engel AG. Monoclonal antibody analysis of mononuclear cells in myopathies. I: Quantitation of subsets according to diagnosis and sites of accumulation and demonstration and counts of muscle fibers invaded by T cells. Ann Neurol 16: 193-208, 1984.

36. Brunn A, Hans VJ, Vogelgesang S, Deckert M. Inflammatory myopathy with abundant macrophages and dermatomyositis: two stages of one disorder or two distinct entities? Acta Neuropathol
118: 793-801, 2009.

37. Caldwell CJ, Swash M, Van der Walt JD, Geddes JF. Focal myositis: a clinicopathological study. Neuromusc Disord 5: 317-321, 1995.

38. Auerbach A, Fanburg-Smith JC, Wang G, Rushing EJ. Focal myositis: a clinicopathologic study of 115 cases of an intramuscular mass-like reactive process. Am J Surg Pathol 33: 1016-1024, 2009.

39. Heffner RR Jr, Barron SA, Jenis EH, Valeski JE. Skeletal muscle in polymyositis. Immunohistochemical study. Arch Pathol Lab Med 103: 310-313, 1979.

40. Naughton M, Jessop JD, Williams BD. Idiopathic recurrent nonsuppurative focal myositis: a report of two cases. Br J Rheumatol 32: 1101-1104, 1993.

41. Sieb JP, Ries F, Träber F, Keller E, Block W, Kaminski M. Recurrent focal myositis. Muscle Nerve 20: 1205-1206, 1997.

42. Kisielinski K, Miltner O, Sellhaus B, Krüger S, Goost H, Siebert $\mathrm{CH}$. Recurrent focal myositis of the peroneal muscles. Rheumatology 41: 1318-1322, 2002.

43. Yadla M, Kishore KC, Sivakumar V, et al. Recurrent focal myositis in a patient on maintenance hemodialysis. Hong Kong $\mathrm{J}$ Nephr 7: 21-23, 2015.

44. Revaz S, Theumann N, Lobrinus JA, So AK, Dudler J. Leg pain due to bilateral focal recurrent myositis in a hemodialysis patient. Am J Kidney Dis 45: e7-e11, 2005.

45. Gordon M, Madhok R. Recurrent focal myositis. Rheumatology 38: 1295-1296, 1999.

46. Teixeira F, Peixoto D, Costa JA, et al. Recurrent focal myositis: a rare inflammatory myopathy. Acta Reumatol Port 39: 172-175, 2014.

47. Garcia-Consuegra J, Morales C, Gonzalez J, Merino R. Relapsing focal myositis: a case report. Clin Exp Rheumatol 13: 395-397, 1995.

48. Snell BJ, Dowd M. Recurrent focal myositis presenting as flexion contractures of the fingers. J Hand Surg Eur 32: 714, 2007.

49. Misu T, Tateyama M, Nakashima I, Shiga Y, Fujihara K, Itoyama Y. Relapsing focal myositis: the localization detected by gallium citrate Ga 67 scintigraphy. Arch Neurol 62: 1930-1931, 2005.

50. Omori H, Mitsui T, Kunishige M, Endo I, Takahashi K, Matsumoto T. Systemic muscular inflammation in a patient with recurrent orbital myositis. Clin Neuropathol 24: 191-193, 2005.

51. Lim KL, Robson K, Powell RJ. Focal myositis: an unusual cause of bilateral upper eyelid swellings. Postgrad Med J 69: 876-878, 1993.

52. Kalden P, Krause T, Volk B, Peter HH, von Kempis J. Myositis of small foot muscles. Rheumatol Int 18: 79-82, 1998.

The Internal Medicine is an Open Access article distributed under the Creative Commons Attribution-NonCommercial-NoDerivatives 4.0 International License. To view the details of this license, please visit (https://creativecommons.org/licenses/ by-nc-nd/4.0/).

(C) 2016 The Japanese Society of Internal Medicine http://www.naika.or.jp/imonline/index.html 